\title{
Study on the Influence of Grid Voltage Quality on SVG and the Suppression
}

\author{
Guiping Yi *, and Renjie Hu **
}

\begin{abstract}
Industrial Static Var Generator (SVG) is typically applied at or near the load center to mitigate voltage fluctuation, flicker, phase unbalance, non-sine distortion or other load-related disturbance. Special attention is paid to the influence of grid voltage quality on SVG current, the non-sine distortion and unbalance of grid voltage causes not only the AC current distortion and unbalance but also the DC voltage fluctuation. In order to let the inverter voltage contain the fundamental negative sequence and harmonic component corresponding to the grid voltage, a new dual-loop control scheme is proposed to suppress the influence in this paper. The harmonic and negative sequence voltage decomposition algorithm and DC voltage control are also introduced. All these analyses can guide the practical applications. The simulation results verify the feasibility and effectiveness of the present control strategy and analyses.
\end{abstract}

Keywords: SVG, Unbalance, Harmonic, Distortion, Dual-loop control

\section{Introduction}

With the fast development of information technology in recent years, the requirement for electricity quality is higher and higher. In addition to require the reliability and continuity of power supply system, stable voltage and frequency are also expected. But the loads of distribution network are increasing, such as rectifier, arc furnace and so on. The nonlinear, impulse and imbalance characteristics of these loads result in distortion of the voltage and current waveforms, voltage fluctuations and flicker. Lightning, short circuit and open circuit in power system can also cause severe disruption to electricity quality. The supply cutting off suddenly will bring enormous economy loss, especially in significant industry. Therefore how to enhance and ensure power quality has been a major topic in the electrical engineering [1].

Static Var Generator (SVG) is an advanced reactive power compensator and it has attracted more and more attentions in recent years. It can be used to control power factor, regulate voltage, stabilize power flow and improve dynamic performance of power systems. SVG can also provide additional functions like harmonics compensator and load balancer, as a potential trend in the past decade. The major advantages of a SVG include faster dynamic response, the ability to generate the rated current at almost any grid voltage, the use of relatively small capacitor on the

\footnotetext{
Southteast University of China, Nanjiang(beyond29@163.com)
}

dc side and a smaller footprint in a substation [2-3].

\section{Impact of non-ideal grid voltage on DC voltage}

The proposed configuration of the whole system is shown in Figure.1. There is no transformer, and the SVG is directly connected in parallel with the three-phase load via a small inductor for attenuation of switching frequency current ripples. The power converter of the SVG employs several series-connected IGBTs in each leg of the threephase bridge circuit for medium voltage blocking capability. The DC capacitors could be in series and parallel connections too. The SVG looks like a voltage source. When the system voltage $U$ includes negative sequence voltage and harmonic voltage, negative sequence current and harmonic current can flow into the compensator limited only by the SVG reactance $\mathrm{X}$, the value of harmonic current can be calculated by (2) [4-6].

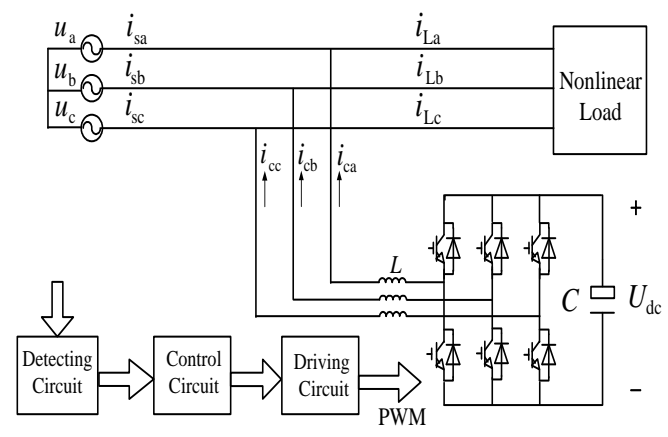

Fig. 1. Structure of SVG 


\section{A. Impact of grid harmonic voltage}

Harmonic voltage content can be derived as follows

$$
\operatorname{HR} U_{n}=\frac{U_{n}}{U_{1}} \times 100 \%
$$

Where Un is the rms value of n-order harmonic voltage, $\mathrm{U} 1$ is the rms value of fundamental positive sequence voltage. When the harmonic voltage content is HRUn, the harmonic current flowing through the SVG is expressed [1]

$$
I_{n}=\frac{U_{n}}{X_{n}}=\frac{U_{l} \mathrm{HR}_{n}}{\sqrt{R^{2}+\left(n \omega_{0} L\right)^{2}}}=\frac{U_{l}}{\sqrt{R^{2}+\left(\omega_{0} L\right)^{2}}}
$$

Assumed that $\varphi 1$ is the phase angle of the fundamental positive sequence current. The harmonic current flowing through the SVG is expressed

$$
\left[\begin{array}{c}
i_{a n} \\
i_{b n} \\
i_{c n}
\end{array}\right]=-I_{n}\left[\begin{array}{c}
\cos \left(n \omega_{0} t+\varphi_{1}\right) \\
\cos \left(n \omega_{0} t+\varphi_{1}+120^{\circ}\right) \\
\cos \left(n \omega_{0} t+\varphi_{1}-120^{\circ}\right)
\end{array}\right]
$$

By considering only the fundamental components, the switching function of the SVG converter can be simplified

$$
\left[\begin{array}{l}
S_{a} \\
S_{b} \\
S_{c}
\end{array}\right]=\frac{\lambda}{2}\left[\begin{array}{c}
\sin \omega_{0} t \\
\sin \left(\omega_{0} t-120^{\circ}\right) \\
\sin \left(\omega_{0} t+120^{\circ}\right)
\end{array}\right]
$$

Where $\lambda$ is modulation depth of the SVG. From (3) (4), we can concluded that:

$$
\begin{aligned}
& i_{d}=S_{a} i_{a n}+S_{b} i_{b n}+S_{c} i_{c n}= \\
& =I_{\mathrm{N}}\left\{\cos \left[(n-1) \omega_{0} t+n \varphi_{1}\right]\left(1+2 \cos \left[(n-1) 120^{\circ}\right]\right)\right. \\
& \left.-\cos \left[(n+1) \omega_{0} t+n \varphi_{1}\right]\left(1+2 \cos \left[(n+1) 120^{\circ}\right]\right)\right\} \\
& u_{d}=i_{n}\left|Z_{c}(\omega)\right|=U_{\mathrm{N}}\left\{\cos \left[(n-1) \omega_{0} t+n \varphi_{1}\right]\left(1+2 \cos \left[(n-1) 120^{\circ}\right]\right)\right. \\
& \left./(n-1)-\cos \left[(n+1) \omega_{0} t+n \varphi_{1}\right]\left(1+2 \cos \left[(n+1) 120^{\circ}\right]\right) /(n+1)\right\}
\end{aligned}
$$

Where: $I_{\mathrm{N}}=\frac{3 \lambda U_{n}}{4 \sqrt{\mathrm{R}^{2}+\left(\mathrm{n} \omega_{0} \mathrm{~L}\right)^{2}}}, U_{N}=\frac{I_{N}}{\omega_{0} C}$

From (6), we can conclude that:

(1) DC voltage fluctuation frequency is only relative to the frequency of harmonic voltage. (2) In case of the presence of $3 \mathrm{k} \pm 1$ order harmonic voltages, a $3 \mathrm{k}$ order harmonic component appears in the dc voltage. Figure 2 3 shows the simulation results $(\mathrm{k}=1,2,3 \ldots)$. (3) $3 \mathrm{k}$ order harmonic voltage has no impact on dc voltage.

DC voltage fluctuation amplitude is relative to the harmonic voltage and modulation depth $\lambda$. When the harmonic voltage is constant, the greater $\lambda$ is, the greater the fluctuation amplitude of $\mathrm{dc}$ voltage. Theoretically, dc voltage fluctuation can be suppressed by reducing $\lambda$. But reducing $\lambda$ will affect waveform quality and increase the content of harmonic currents. And lower $\lambda$ requires a higher $\mathrm{dc}$ voltage in the case of an certain rated capacity. In order to reduce the content of harmonic currents and improve the reliability of SVG, lower dc voltage with a higher $\lambda$ is usually used.

\begin{tabular}{|c|c|c|c|}
\hline \multirow{2}{*}{$\begin{array}{l}5 \text { order } \\
\text { harmo } \\
\text { nic }\end{array}$} & \multirow{2}{*}{$\begin{array}{l}\text { Theore } \\
\text { tical } \\
\text { value( } \\
(V)\end{array}$} & \multicolumn{2}{|c|}{ Simulation value $(V)$} \\
\hline & & $\begin{array}{l}\mathrm{U}_{\mathrm{dc}}=60 \\
0 \mathrm{~V}\end{array}$ & $\begin{array}{l}\mathrm{U}_{\mathrm{dc}}=80 \\
0 \mathrm{~V}\end{array}$ \\
\hline $3 \%$ & 0.923 & 0.915 & 0.937 \\
\hline $5 \%$ & 1.44 & 1.41 & 1.43 \\
\hline $10 \%$ & 2.67 & 2.65 & 2.66 \\
\hline $15 \%$ & 4.89 & 4.87 & 4.87 \\
\hline $20 \%$ & 7.74 & 7.75 & 7.76 \\
\hline
\end{tabular}

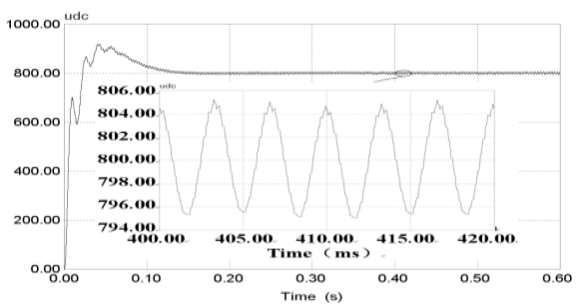

Fig. 2. DC voltage while grid contains $30 \% 5$ order harmonic voltage.

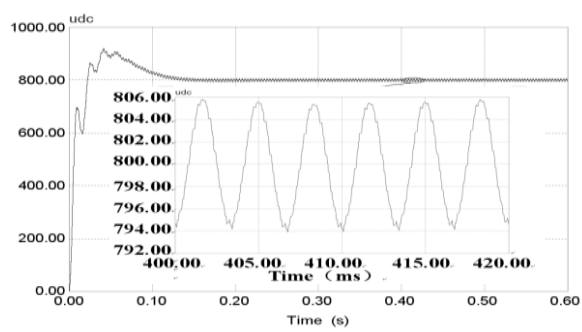

Fig. 3. DC voltage while grid contains $50 \% 7$ order harmonic voltage.

Table. 1 Relationship between dc voltage fluctuation and 5 order $\mathrm{h}$ armonic

Table. 1 shows the relationship between the amplitude of dc voltage fluctuations and 5 order harmonic voltage. From table 1, we infer:

(1) Simulation value is close to the value calculated by (6).

(2) The amplitude of dc voltage fluctuation is irrelevant to the dc voltage. 


\section{B. Impact of grid negative sequence voltage}

Negative sequence voltage content can be quantified using the following definition[3-6]

$$
K_{-}=\frac{U_{-}}{U_{1}} \times 100 \%
$$

Where $\mathrm{U}$ - is the rms value of the negative sequence voltage. When the negative sequence voltage content is $\mathrm{K}$-, the negative sequence current flowing through the SVG is

$$
I_{-}=\frac{U_{-}}{X_{-}}=\frac{K_{-} U_{1}}{\sqrt{R^{2}+\left(\omega_{0} L\right)^{2}}}
$$

Assumed that $\varphi 2$ is the phase angle of the fundamental negative sequence current, the negative sequence current is

$$
\left[\begin{array}{l}
i_{a_{-}} \\
i_{b_{-}} \\
i_{c_{-}}
\end{array}\right]=I_{-}\left[\begin{array}{c}
\sin \left(\omega_{0} t+\varphi_{2}\right) \\
\sin \left(\omega_{0} t+\varphi_{2}+120^{\circ}\right) \\
\sin \left(\omega_{0} t+\varphi_{2}-120^{\circ}\right)
\end{array}\right]
$$

By considering only the fundamental frequency components, the switching function of the SVG converter can be simplified as (4). From (4) and (9), we obtain:

$$
\begin{array}{r}
i_{d}=S_{a} i_{a_{-}}+S_{b} i_{b_{-}}+S_{c} i_{c_{-}}=I^{-} \cos \left(2 \omega_{0} t+\varphi_{2}\right) \\
u_{d}=i_{d}\left|Z_{c}(\omega)\right|=U^{-} \cos \left(2 \omega_{0} t+\varphi_{2}\right) / 2 \\
\text { Where: } \quad I^{-}=\frac{3 \lambda U_{-}}{4 \sqrt{\mathrm{R}^{2}+\left(\omega_{0} \mathrm{~L}\right)^{2}}}, U^{-}=\frac{I^{-}}{\omega_{0} C}
\end{array}
$$

From (11), we can see that negative sequence voltages causes a second harmonic component in the dc voltage. Fluctuation amplitude is relative to the negative sequence voltage and the modulation depth $\lambda$. Figure 4 shows the simulation results.

Table 2 shows the relationship between the amplitude of dc voltage fluctuations and negative sequence voltage. From table 2, we can obtain that:

(1) Simulation value is close to the theoretical value calculated by (11).

(2) The amplitude of dc voltage fluctuation is irrelevant to the dc voltage.

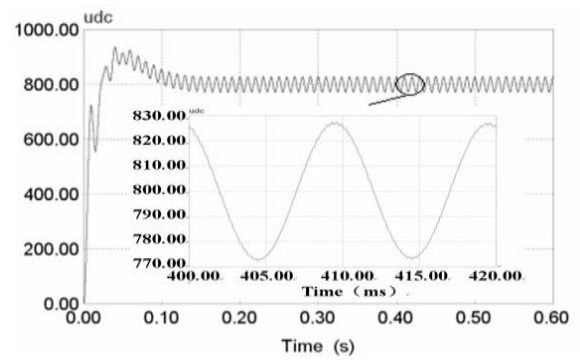

Fig. 4. DC voltage while grid contains $10 \%$ negative sequence voltage.

Table. 2 Relationship between dc voltage fluctuation and unbalance.

\begin{tabular}{|c|c|c|c|}
\hline \multirow{2}{*}{$\begin{array}{c}\text { Negative sequence } \\
\text { voltage amplitude } \\
\text { value }(V)\end{array}$} & $\begin{array}{c}\text { Calculat } \\
\text { ed } \\
\text { value }(V)\end{array}$ & \multicolumn{2}{|c|}{$\begin{array}{c}\text { Simulation } \\
\text { value }(V)\end{array}$} \\
\cline { 2 - 4 } & $\begin{array}{r}\mathrm{U}_{\mathrm{dc}} \\
\mathrm{Ud}\end{array}$ & $\begin{array}{c}\mathrm{U} \\
\mathrm{dc}=80 \\
0 \mathrm{~V}\end{array}$ \\
\hline 6.43 & 8.65 & $\begin{array}{c}10 . \\
4\end{array}$ & $\begin{array}{c}1 \\
0.3\end{array}$ \\
\hline 13.14 & 16.6 & $6 \begin{array}{c}20 \\
6\end{array}$ & 0.5 \\
\hline 17.66 & 25.4 & $5^{31 .}$ & $\begin{array}{c}3 \\
1.4\end{array}$ \\
\hline 25.08 & 33.2 & $\begin{array}{c}41 . \\
4\end{array}$ & 2.1 \\
\hline 32.3 & 42.5 & $\begin{array}{c}53 . \\
5\end{array}$ \\
\hline
\end{tabular}

\section{Influence of non-ideal grid voltage on the AC current}

\section{A. Influence of grid negative sequence voltage}

The SVG ac current includes negative sequence current when the grid includes negative sequence voltage. The amplitude of the negative current can be calculated by (8) [6-10].

We assume that dc voltage is constant while analyzing the effect of the negative sequence voltage on the ac current From Figure 5, we obtain that the ac current appears obvious unbalance when the grid voltages include $1 \%$ negative sequence voltage. Figure 6 shows that the simulation value of negative sequence current is close to the theoretical value.

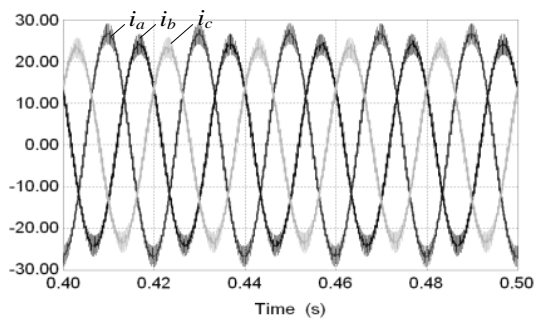

Fig. 5. Output current while grid contains $1 \%$ negative sequence voltage. 


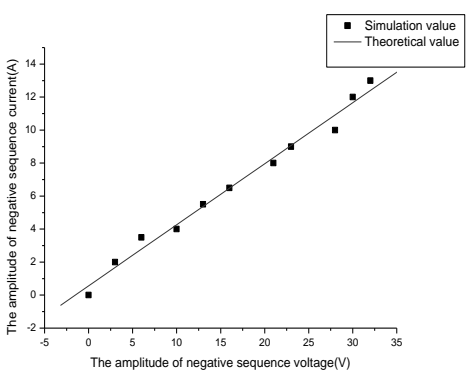

Fig. 6. Relationship between the amplitude of negative sequence current and negative sequence voltage.

\section{B. Influence of grid harmonic voltage}

Taking 5 order harmonic as an example. The ac current appears corresponding number harmonic current when grid voltage includes harmonic voltage. (12) can calculate current amplitude[2].

$$
I_{5}=\frac{U_{1} \mathrm{HR} U_{5}}{\sqrt{R^{2}+\left(5 \omega_{0} L\right)^{2}}}
$$

Assume that dc voltage is constant. From Figure 7, we obtain that the output current appears obvious harmonic current when the grid voltage include $5 \% 5$ order harmonic voltage. Figure 8 shows the simulation value of harmonic current closed to the theoretical value.

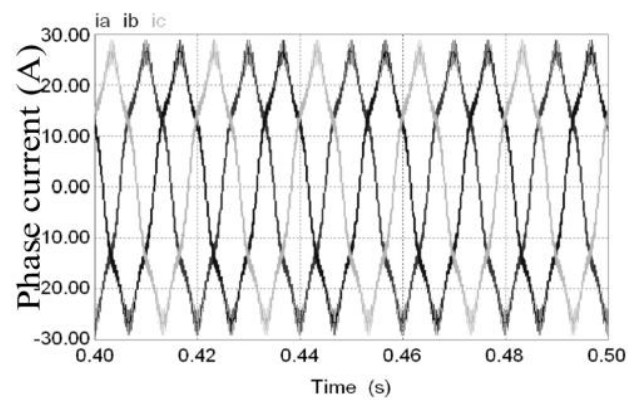

Fig. 7. Output current while grid contains $5 \% 5$ order harmonic voltage.

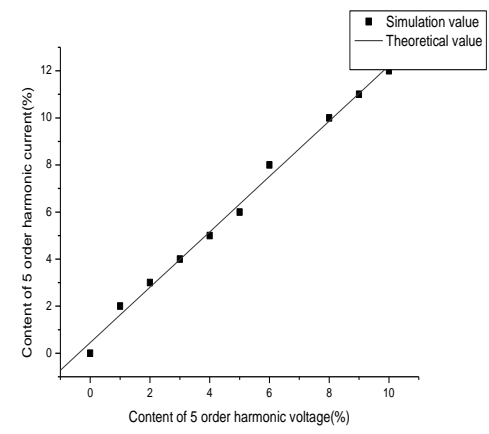

Fig. 8. Relationship between 5 order harmonic current and 5 order harmonic voltage.

\section{Influence of non-ideal DC voltage fluctuations on the AC current of SVG}

A dc voltage with fluctuations can be expressed as:

$$
U_{d c}=U_{d c 0}\left[1+k \sin \left(n \omega_{0} t\right)\right]
$$

Where Udc0 is the average voltage, $\mathrm{k}$ is fluctuation coefficient and n $\omega 0$ is fluctuation frequency. The output voltage of SVG can be expressed as:

$$
\left[\begin{array}{c}
U_{G a} \\
U_{G b} \\
U_{G c}
\end{array}\right]=\frac{1}{2} \lambda U_{d c}\left[\begin{array}{c}
\sin \left(\omega_{0} t+\varphi\right) \\
\sin \left(\omega_{0} t-120^{\circ}+\varphi\right) \\
\sin \left(\omega_{0} t+120^{\circ}+\varphi\right)
\end{array}\right]
$$

Substitute (13) into (14), we can obtain:

$$
\begin{aligned}
& U_{G a}=\lambda U_{d c 0} \sin \left(\omega_{0} t+\varphi\right) / 2+\lambda k U_{d c 0} \cos [(n-1) \\
& \left.\omega_{0} t-\varphi\right] / 4-\lambda k U_{d c 0} \cos \left[(n+1) \omega_{0} t+\varphi\right] / 4
\end{aligned}
$$

$$
\begin{aligned}
& U_{G b}=\lambda U_{d c 0} \sin \left(\omega_{0} t+\varphi-120^{\circ}\right) / 2+\lambda k U_{d c 0} \cos [(n-1) \\
& \left.\omega_{0} t-\varphi+120^{\circ}\right] / 2-\lambda k U_{d c 0} \cos \left[(n+1) \omega_{0} t+\varphi-120^{\circ}\right] / 2 \\
& U_{G c}=\lambda U_{d c 0} \sin \left(\omega_{0} t+\varphi+120^{\circ}\right) / 2+\lambda k U_{d c 0} \cos [(n-1) \\
& \left.\omega_{0} t-\varphi-120^{\circ}\right] / 2-\lambda k U_{d c 0} \cos \left[(n+1) \omega_{0} t+\varphi+120^{\circ}\right] / 4
\end{aligned}
$$

From (15) (17) we can see that $n \pm 1$ order harmonic

\begin{tabular}{|c|c|c|c|c|c|}
\hline \multirow{2}{*}{$\begin{array}{l}\text { Fluctuation } \\
\text { frequency }(\mathrm{Hz})\end{array}$} & \multicolumn{5}{|c|}{ Harmonic current $(A)$} \\
\hline & $\begin{array}{l}\text { Neg - } \\
\text { Sequence }\end{array}$ & 3order & 5order & 7order & 9order \\
\hline 100 & 9.79 & 4.86 & 0.02 & 0.03 & 0.02 \\
\hline 200 & 0.34 & 4.93 & 2.85 & 0.03 & 0.03 \\
\hline 400 & 0.28 & 0.08 & 0.01 & 2.12 & 1.64 \\
\hline
\end{tabular}
current appears in the ac current when dc voltage has $n$ order harmonic fluctuations. Table 3 shows the relationship between dc fluctuation frequency and a phase output current when fluctuation amplitude of dc voltage is $160 \mathrm{~V}$. From table 3, we obtain that $\mathrm{n} \pm 1$ order harmonic current appears in the output current indeed when dc voltage has $n$ order harmonic fluctuations.

Table. 3 DC fluctuation frequency and a phase output current 


\section{Control strategy}

To restrain the harmonic and negative sequence currents which are the consequence of harmonic and unbalanced grid voltage, a control strategy is proposed in this paper. The control block diagram is shown in Figure 9, it contains two major sections, one is the positive sequence control loop, the other is negative sequence control loop. The inputs of dual-loop control are the current generated by SVG and the grid voltage. The current is divided into positive sequence component and negative sequence component, which is fed into positive sequence control loop and negative sequence control loop. The sum of output signal of positive and negative sequence control loop can be used as voltage of impedance. The difference between grid voltage and sum can be used as modulation signal [6-8].

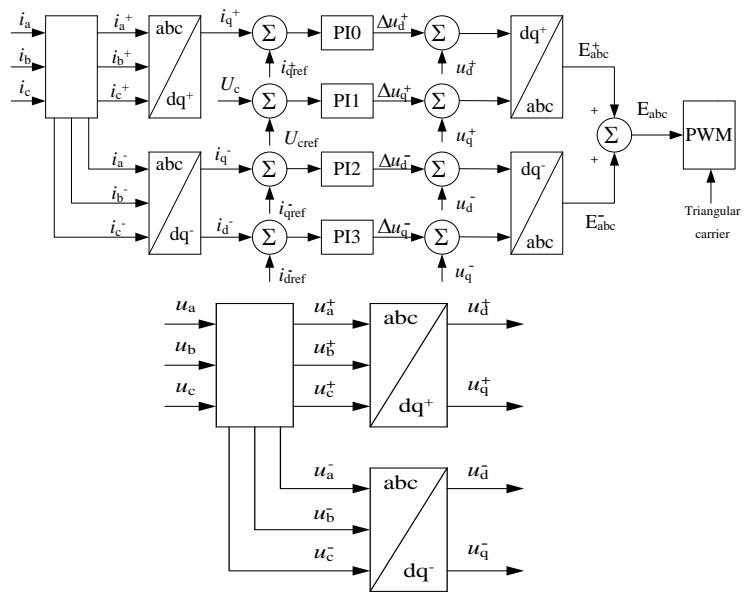

(a) The control block diagram

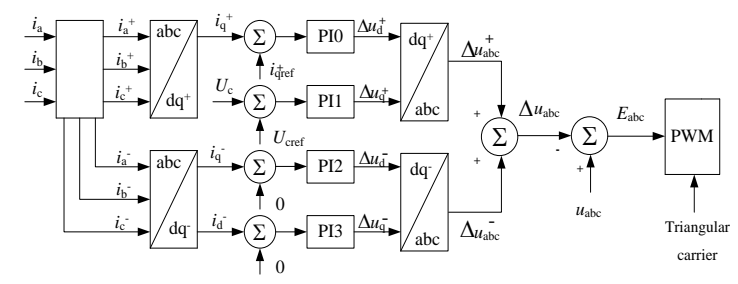

(b) A simplified control block diagram

Fig. 9. The block diagram of dual-loop control.

The positive sequence control loop consists of two loops, PI0 and PI1; the negative sequence control loop also consists of two loops, PI2 and PI3. PI0 and PI2 are to control reactive current. Their inputs are the difference between the reference reactive current and the reactive current generated by SVG. Their outputs can be used as the reactor voltage generated by reactive current. PI1 and PI3 are to control active current. Their outputs can be used as the reactor voltage generated by active current. The input of PI1 is the same to dc voltage control loop. The input of PI3 is the difference between the reference active current and the active current generated by SVG. The outputs of positive sequence control loop are the fundamental positive sequence voltage of reactance; the outputs of negative sequence control loop are the fundamental negative sequence voltage of reactance.

\section{Reference detection and energy flow}

In order to compensate grid voltage harmonic and unbalance real-timely, this paper adopts voltage detection algorithm based on synchronous rotating coordinate $\mathrm{d}-\mathrm{q}$ transformation method, the block diagram is shown in Figure 10. This detection algorithm can separate harmonic and negative sequence voltage accurately, real-timely, and it has a good dynamic-state and steady-state performance [710].

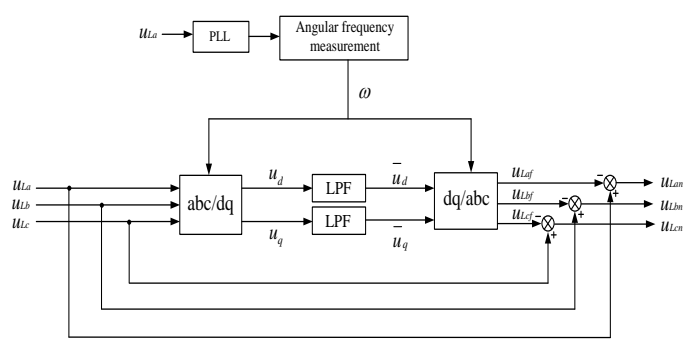

Fig. 10. The algorithm of reference voltage decomposition.

Here, grid voltage uLa, uLb, uLc can change into d axis component $\mathrm{ud}$ and $\mathrm{q}$ axis component uq after $\mathrm{d}-\mathrm{q}$ transformation, i.e.

$$
\left[\begin{array}{l}
u_{d} \\
u_{q}
\end{array}\right]=c\left[\begin{array}{l}
u_{L a} \\
u_{L b} \\
u_{L c}
\end{array}\right]
$$

Where

$$
c=\frac{2}{3}\left[\begin{array}{lll}
\sin \omega t & \sin (\omega t-2 \pi / 3) & \sin (\omega t+2 \pi / 3) \\
\cos \omega t & \cos (\omega t-2 \pi / 3) & \cos (\omega t+2 \pi / 3)
\end{array}\right]
$$

Then, after filtered by LPF, the DC component $\bar{u}_{d}$ and $\bar{u}_{q}$ are derived, once again, it can obtain the fundamental positive sequence component $u_{\text {Laf }}, u_{\text {Lbf }}, u_{L c f}$ by inverse transformation.

$$
\left[\begin{array}{l}
u_{L a f} \\
u_{L b f} \\
u_{L c f}
\end{array}\right]=c^{-1}\left[\begin{array}{l}
-\bar{u}_{d} \\
\bar{u}_{q}
\end{array}\right]
$$


In (20)

$$
c^{-1}=\frac{2}{3}\left[\begin{array}{cc}
\sin \omega t & \cos \omega t \\
\sin (\omega t-2 \pi / 3) & \cos (\omega t-2 \pi / 3) \\
\sin (\omega t+2 \pi / 3) & \cos (\omega t+2 \pi / 3)
\end{array}\right]
$$

Where, $\bar{u}_{d}$ and $\bar{u}_{q}$ are produced by $u_{L a f}, u_{L b f}, u_{L c f}$, so $u_{L a f}, u_{L b f}, u_{L c f}$ can be calculated by $\bar{u}_{d}$ and $\bar{u}_{q}$. Then, the total of harmonic and negative sequence voltage $u_{L a n}, u_{L b n}, u_{L c n}$ can be obtained by the difference of $u_{L a f}, u_{L b f}, u_{L c f}$ and $u_{L a}, u_{L b}, u_{L c}$.

In SVG system, regardless of harmonic compensation or negative sequence unbalance voltage compensation, in the final analysis, it is energy exchange between the device and the grid, that is the energy flow between the SVG DC side energy storage element and the grid, which determines the compensation effect of system and feasibility of control strategy. Generally, the fundamental positive sequence current flowing SVG is zero, so the active power absorbed by the SVG is determined by the negative sequence component. In grid of symmetrical voltage, the exchange is mainly reactive power between SVG and grid, while the absorption of active power is close to zero. In actual operation, in order to maintain the stability of the DC side voltage, the active power absorbed by the SVG should be controlled effectively.

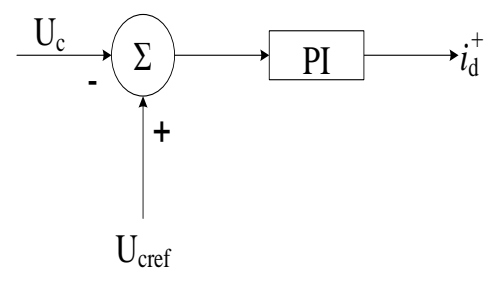

Fig. 11. DC voltage control.

Figure 11 is the DC voltage control. The difference between feedback value and given value of the DC side voltage is controlled by PI (proportional integrational) controller, then, the active reference $i_{d}^{+}$is obtained. Once more, active reference current of SVG in time domain is derived after calculation. The compensation circuit produces compensation current flowing into the grid according to reference signal, thus, compensation current of SVG will contain fundamental active current component, so that energy exchange occurs between the DC side and AC side of SVG, the DC side voltage is regulated to given value[10].

\section{Simulation results}

In order to verify the validity of the analyses, the simulation results based on the SVG are shown in Figures as follows. The fully digital and dual-loop control strategy is used. Where $\mathrm{Udc}=800 \mathrm{~V}, \mathrm{C}=750 \mathrm{uF}, \quad u_{\mathrm{a}}=311 \mathrm{co} \omega \mathrm{t}$, the connected reactor value of the compensator is $4.5 \mathrm{mH}$, the capacity of SVG is $20 \mathrm{kvar}$.

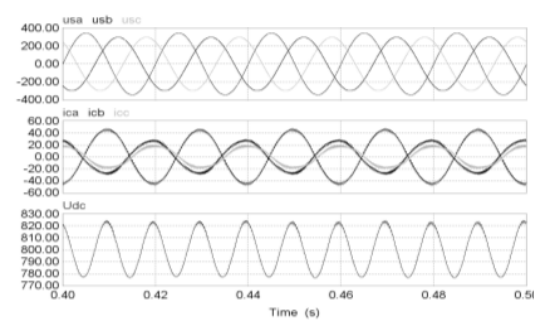

(a) before compensation

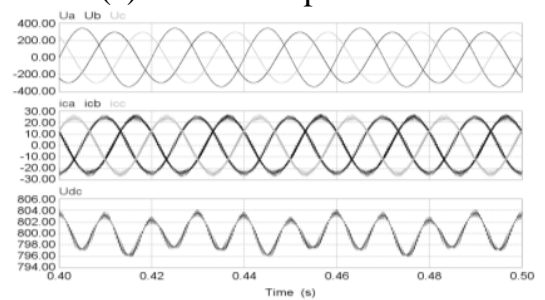

(b) after compensation

Fig. 12. SVG response to $10 \%$ unbalanced grid-voltage.

When the SVG responds to $10 \%$ unbalanced grid voltage before compensation, the simulation result is shown in Figure 12(a). Due to the adoption of control strategy, the fundamental negative sequence current of individual phase is lower than $0.5 \%$ after compensation, the simulation result is shown in Figure 12(b). The dc voltage is still steady around the set value and a 2 order harmonic component appears under the condition of unbalanced voltage.

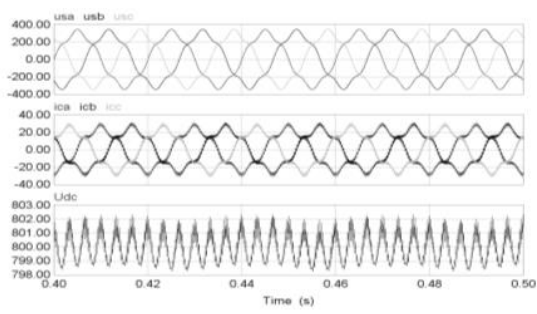

(a) before compensation

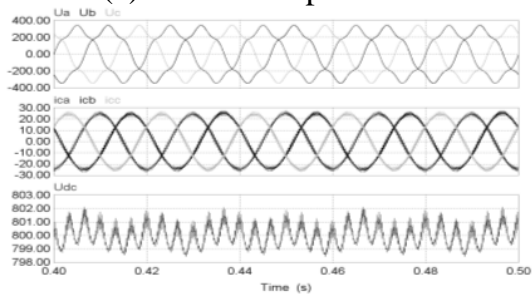

(b) after compensation

Fig. 13. SVG response to $10 \% 5$ order harmonic gridvoltage. 
When the SVG responds to $10 \% 5$ order harmonic grid voltage before compensation, the simulation result is shown in Figure 13 (a). Due to the application of control strategy, the 5 order harmonic current are lower than $1 \%$ after compensation, the simulation result is shown in Figure 13(b). The dc voltage is still steady around the given value $800 \mathrm{~V}$.

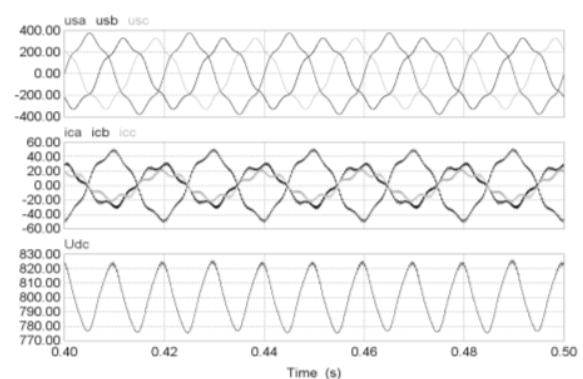

(a) before compensation

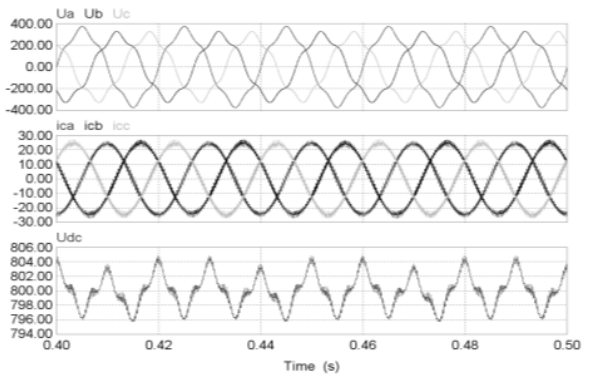

(c) after compensation

Fig. 14. SVG response to $10 \%$ unbalanced grid-voltage and $10 \% 5$ order harmonic grid-voltage.

When the SVG responds to $10 \%$ unbalanced and $10 \% 5$ order harmonic grid voltage before compensation, the simulation result is shown in Figure 14(a). Because of the dual-loop control strategy, the fundamental negative sequence and 5 order harmonic current of individual phase is lower than $1 \%$ after compensation, the simulation result is shown in Figure 14(b). The dc voltage remains stable at the reference value $800 \mathrm{~V}$.

\section{Conclusions}

In this paper, detailed analyses and design considerations are carried out to look into the influence of system voltage quality on SVG. The harmonic and negative components of grid voltage will cause the fluctuation of SVG dc voltage and also result in harmful components of ac current. A control strategy is proposed to suppress the influence of non-ideal grid voltage on the ac current. All these analyses can guide the practical applications, a reliable compensator will be designed. The simulation results verify the validity and feasibility of above analyses and conclusions.

\section{REFERENCES}

[1] R. D. Henderson, P. J. Rose, "Harmonics: The effects on power quality and transformers," IEEE Transactions on Industrial Applications, Vol. 30, No. 3, pp. 528-532, 1994.

[2] Kale. M, Ozdemir. E, "Harmonic and reactive power compensation with shunt active power filter under non-ideal mains voltage," Electric Power Systems Research, Vol. 74, No. 3, pp. 363-370, 2005.

[3] Mohaddes.M, Gole.A.M,Elez.S, "Steady state frequency response of STATCOM," IEEE Transactions on Power Delivery, Vol. 16, No. 1, pp. 18-23, 2001.

[4] Li Xiaolu, Duan Xianzhong, He Yangzan, "Dynamic model of ASVG in unbalanced systems," Proceedings of the CSEE, Vol. 19, No. 9, pp. 76-80, 1999.

[5] Sensarma P S, Padiyar K R, Ramanarayanan V, "Analysis and performance evaluation of a distribution STATCOM for compensation voltage fluctuations," IEEE Transactions on Power Delivery, Vol. 16, No. 2, pp. 259-264, 2001.

[6] Rong Fei, Luo An, Fan Qing, "A novel voltage control method applied in STATCOM under unbalanced system," Transactions of China Electrotechnical Society, Vol. 25, No. 3, pp. 138-143, 2010.

[7] Tang Jie, Luo An, Zhou Ke, "Design and realization voltage control for static synchronous compensator," Transactions of China Electrotechnical Society, Vol. 21, No. 8, pp. 103-107, 2006.

[8] Hochgraf C, Lasseter R H, "Statcom controls for operation with unbalanced voltages," IEEE Transactions on Power Delivery, Vol. 13, No. 2, pp. 538-544, 1998.

[9] Chen W L,Hsu Y Y, "Direct output voltage control of a static synchronous compensator using current sensorless d-q vector-based power balancing scheme," IEEE Transactions on Power Delivery, Vol. 2, No. 7-12, pp. 545-549, 2003.

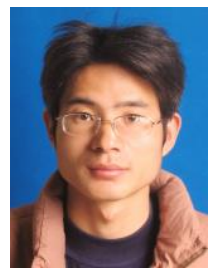

Gui-Ping Yi was born in jiangxi, China, on July 4, 1981. He received the B.S. degree from the College of Electrical and Information Engineering, Nanchang University in 2004, and the M.S. degree from the College of Electric Power and Automation Engineering, Shanghai University of Electric Power in 2010, respectively. He is presently a Ph.D. student in Southteast University, Nanjing, China. His research interests include micro-grid power quality, electric power saving, reactive power compensation, and active power filters.

Ren-Jie Hu was born in ZheJiang, China, on May 12, 1962 He received the B.S. , M.S. and Ph.D. degrees in electrical engineering from Southteast University, in 1985, 1994 and 2002, respectively. He has been with the Department of Electrical Engineering, Southteast University, where he is currently a Professor and serves as the chief of Electrical and Electronic Experiment Center. His research interests are power electronics and power delivery, distributed generation, power quality management and super capacitor energy storage. 